Bonomo, D. - Vazio e fastio em Faserland

\title{
Vazio e fastio em Faserland, de Christian Kracht
}

\author{
[Emptiness and fastidiousness in Christian Kracht's Faserland]
}

Daniel R. Bonomo ${ }^{1}$

\begin{abstract}
If not one of the best, Christian Kracht is certainly one of the most talked about authors of fiction in the German language nowadays. His carreer goes back to 1995, when his first novel Faserland was published - an event which helped to shape the so called Popliteratur. However, whether it is the zero hour of a work composed of other good moments or whether it is the literary mark of a generation, Faserland is not only an example of a pop reality. It has also deserved frequent reading and interpretations, reprints and critical approaches, attracting by these means the attention of literary historiography. The novel narrates a few days' wanderings of a narcotized and affluent young man from Northern to Southern Germany reaching as far as Switzerland. There is no great adventure in the story, but the book leaves rather an impression of emptiness and fastidiousness which accompanies a senseless life. In this text, I investigate the kind of boredom produced by Faserland.
\end{abstract}

Keywords: Christian Kracht; Faserland; Contemporary German Literature; Boredom

Resumo: Christian Kracht é hoje, se não dos melhores, certamente dos mais comentados autores da ficção de língua alemã. Seu trajeto recua a 1995, ano da publicação de Faserland, o primeiro romance, que aliás distinguiu as balizas daquela que, nessa década, se chamou Popliteratur. Mas, seja a hora zero de uma obra composta de outros bons momentos, seja o ponteiro literário de uma geração, Faserland não é só exemplo pop, tem merecido constantes leituras, sempre novas tiragens, abordagens críticas e assim também a atenção da historiografia literária. No romance são narrados alguns poucos dias da vida narcotizada de um jovem endinheirado e meio sem rumo, do Norte ao Sul da Alemanha, até a Suíça. Nada extraordinário, nenhuma grande peripécia, nenhuma aventura, senão a impressão de um vazio todo presente e o fastio, força do aborrecimento. No texto, investigo que espécie de aborrecimento produz Faserland.

Palavras-chave: Christian Kracht; Faserland; Literatura alemã contemporânea; Aborrecimento

\footnotetext{
${ }^{1}$ Doutor em Língua e Literatura Alemã pela Universidade de São Paulo. E-mail: drbonomo@gmail.com
}

Pandaemonium, São Paulo, v. 17, n. 23, Jun /2014, p. 68-82 


\section{Bonomo, D. - Vazio e fastio em Faserland}

Christian Kracht, nascido suíço, é hoje se não dos mais competentes por certo dos mais comentados escritores contemporâneos de língua alemã. Sua popularidade deve-se, em parte, à qualidade da obra, em parte, à imagem controvertida do autor e à provocação e interesse de seus temas. O último romance, Imperium (2012), motivou uma acusação severa às supostas intenções de Kracht, que prezariam um patrimônio ideológico direitista. Refiro-me ao texto de Georg DIEZ publicado na revista Der Spiegel, em fevereiro de 2012. Para Diez, as coordenadas da literatura de Kracht, de seus heróis, seriam o "aniquilamento" e a "redenção" do homem, e suas escolhas seriam perversamente fascinadas por realidades antidemocráticas. ${ }^{2} \mathrm{Na}$ ocasião, escritores como Daniel Kehlmann e Elfriede Jelinek falaram em defesa de Kracht, censurando, por sua vez, o crítico que teria "transposto os limites entre crítica e denúncia". ${ }^{3}$ A discussão não é sem importância, mesmo a "denúncia" pode não ser tão somente infundada, ainda que não dê conta das dificuldades do significado literário, sobretudo se se pensa em tempos de confusão política e no caso de um good seller como Kracht. O artista e a literatura não estão a salvo, produzem política e nesse sentido o proveito talvez seja que livros não vivem de intenções. As de Kracht aliás permanecem até certo ponto desconhecidas. São comumente deduzidas da obra e de entrevistas em que demonstra saber encenar uma personalidade duvidosa, dissimulada, nunca exatamente comprometida com aquilo que afirma. Por ocasião da leitura pública de seu último romance em Leipzig, valendose da expectativa de sua visita à feira de livros da cidade após a polêmica com os supostos direitismos, preferiu calar a responder às reprimendas recentes e tampouco fez comentários pontuais sobre Imperium. Tira vantagem, assim, do silêncio e da ambiguidade, na vida e na obra. Mas isso afinal é novidade nenhuma.

A questão, como leitor e crítico, é como aproveitar-se dessa ambiguidade. NIETZSCHE dizia que por detrás de um artista medíocre é possível encontrar um homem notável (2005: 69). O inverso parece igualmente possível. Trata-se de confusão frequente, também entre os que avaliam o alcance da criação alheia. Diderot, com o músico sobrinho de Rameau, dizia que "é tão fácil ser um homem de espírito e ter o ar de um tolo quanto esconder um tolo sob uma fisionomia espiritual" (2006: 97). Desse

\footnotetext{
2 "Krachts Koordinaten waren immer Vernichtung und Erlösung. Er platzierte sich damit sehr bewusst außerhalb des demokratischen Diskurses." (DIEZ 2012: 101)

${ }^{3}$ Cf. texto de Iris Radisch publicado no jornal Die Zeit em 23 de fevereiro de 2012.
} 
Bonomo, D. - Vazio e fastio em Faserland

modo, não faço pouco da inteligência de Kracht. Quero, ao contrário, percebê-la em Faserland, seu primeiro romance.

Faserland foi publicado em 1995 e de certa forma distinguiu as balizas daquela que, nessa década, se chamou Popliteratur. De lá para cá, o livro foi traduzido para o japonês, hebraico, lituano e mais línguas, e permanece reeditado, considerado um marco para a "literatura pop" e para a "geração Golf". ${ }^{4}$ Moritz BAßLER fala de Kracht como "fenômeno fundador" (Gründungsphänomen) e de Faserland como "documento fundador" (Gründungsdokument) (2002: 110-11). Mas, como parcela literária de um quadro pop, o livro parece apontar para uma realidade cultural maior, já configurada sob alguns aspectos nos anos de 1980. Como nota Thomas HECKEN (2011), em contexto alemão, alguns dos principais elementos que caracterizam as concepções de mundo vinculadas à literatura pop da década de 90 são na verdade reconhecíveis já anos antes na recusa a valores associados às décadas de 60 e 70. No início dos anos de 1980, qualificadas de pop, diz Hecken, dimensões como "superficialidade", "exterioridade", "materialismo", "descomplicação" e "limitação" avançam sobre a "profundidade", a "interioridade", a "inimizade ao consumismo" e a "abertura formal" da arte alternativa e politizada que distingue os anos de 1970 (cf. HECKEN 2011: 13). Com o fim da República Democrática Alemã e os caminhos abertos com a Reunificação, percebe-se que muita coisa, na configuração político-econômica da cultura do consumo e do consumo cultural, contribuiu para a manutenção dessa realidade por assim dizer pop, que se impõe autoritária e ideologicamente hegemônica em tantos lugares hoje. Num certo sentido, ainda que se trate de simplificar a dinâmica histórica, composta sempre de reações e movimentos contingentes, em períodos agitados como são as últimas décadas do século XX, tomar esse estado de coisas reduzido por diagnóstico de época é olhar para a face de plástico e espetáculo familiar à "cultura global" dos dias atuais. Em Faserland - a ironia patente do "s" que pronuncia mal o "th", do inglês, de fatherland, "pátria" -, esse mundo tem sua versão sofisticada e não menos descartável conformada com os padrões do jovem rico alemão de início dos anos de 1990.

No que respeita aos antecedentes literários de Faserland, foi assinalado desde sua publicação - mostra MERTENS (2003) - o nome de Bret Easton ElLIS, autor de American Psycho, romance publicado em 1991 e composto de drogas, violência e

\footnotetext{
${ }^{4}$ A definição vem de Florian ILLIES que intitula seu livro, publicado em 2000, de Generation Golf, no qual apresenta a geração dos jovens dos anos de 1980 como acrítica, hedonista e consumista.
} 


\section{Bonomo, D. - Vazio e fastio em Faserland}

consumo dilatados de acordo com o gosto (tantas vezes sádico) estadunidense. Aliás, por ser universo jovem e a seu modo transgressor, é possível ainda recuar a Salinger (The Catcher in the Rye) e a momentos da Geração Beat (On the Road, de Jack Kerouac, por exemplo), expandindo sua modalidade romanesca, apesar das diferenças de situação, até os anos de 1950. Pois também Faserland é o romance de um jovem e contém muita realidade adolescente. Como tais, são provocações - não meras provocações - à vida aparentemente confortável dos padrões sociais assentados. No entanto, o personagem de Kracht, como o de Ellis, marcando seu lugar histórico, não repõe a atitude contestadora do jovem que nasce com os anos de 1950 e culmina nos levantes de 68. O protagonista de Kracht não é só indiferente a toda luta política, mas vai a manifestações apenas pelo sentimento do perigo e o restante é rotina. Quando, em determinado trecho, pergunta por um bar, diz querer não algum frequentado por jovens cabeludos, mas por gente "normal". As drogas, por sua vez, não significam possibilidades de transcendência ou conhecimento, não descortinam dimensões e tampouco libertam das convenções da sobriedade burguesa, mas são oportunidades letárgicas consumidas por hábito. Por fim, o personagem de Faserland vai distante das causas coletivas, cultiva a consciência e a distinção de pertencer à minoria rica e não vê problema nisso.

O romance é construído por uma viagem em oito capítulos, um percurso de poucos dias de um narrador jovem, endinheirado e meio sem rumo, constantemente embriagado, do Norte ao Sul da Alemanha, até a Suíça. A história começa em Sylt, ilha localizada nos confins da Alemanha com a Dinamarca, hoje conhecida por seus restaurantes finos e campos de golfe. As outras estações são Hamburgo, Frankfurt, Heidelberg, Munique, Meersburg, na fronteira com a Suíça, e Zurique. Em cada um desses lugares, há desencontros com amigos e estranhos, passagens por festas e quartos de hotéis, e a própria viagem: trechos com automóvel, outros com trem, avião, táxis, caronas e finalmente um barco que não chega à margem seguinte antes do fim do livro, endossando a ausência de fins que define a existência do protagonista. A linguagem é "simples", tem ritmo próximo ao da fala, marcações orais (muito also, na ja, ich meine)

e uma retórica jovem, artificialmente espontânea, às vezes afirmativa - e consequentemente negativa, pontuada com expressões do tipo gar nicht ou adjetivações como blöd ou verdammt, que acompanham muitos nomes -, às vezes indiferente (orações rematadas com oder so ähnlich, oder irgendsowas), às vezes indecisa e 


\section{Bonomo, D. - Vazio e fastio em Faserland}

corretiva (ich weiß nicht, ob ich mich da richtig ausdrücke), outras vezes feita de frases infantis ou anotações triviais, observações insignificantes - e que adquirem significado por isso mesmo, quer dizer, por sua franca insignificância - como "der Himmel ist blau" (2002: 13) $)^{5}$, “der Pullover ist wirklich hübsch" (17) ou "ich fühle mich Scheiße" (104).

Outro traço estilístico que salta à vista em Faserland é a referência exagerada a produtos e marcas. O procedimento não é precisamente novo, isto é, a simples inclusão textual da marca de alguma coisa não é exatamente inédita. Em Schnitzler, por exemplo, a senhorita Else falava em tomar Veronal, barbitúrico bastante consumido como sonífero durante a primeira metade do século $\mathrm{XX}$ e cujo uso exagerado levava facilmente à morte; em Kracht, a medicina é Valium, ansiolítico talvez menos arriscado. Até aí a diferença é pouca. O alívio do sedativo também não é novidade. Mas em Faserland há um excesso, as marcas proliferam à vontade e são mais que os nomes das coisas, compõem seu universo e produzem um texto de certa forma cifrado. Ou seja, cada menção a alguma marca traz consigo sinais mais ou menos ocultos de distinção: são roupas e carros que distinguem pessoas ou grupos de pessoas, também de maneira evidente. Se o leitor participa desse conhecimento, se tem recursos para identificar os elementos fetichistas dessa cultura, em que a associação a marcas assume traços identitários e preconiza comportamentos, não importa de fato. É sempre possível reconhecer que há algo em jogo quando o narrador diz $x$ e não $y$. Importante, a meu ver, é sua consequência para a configuração simbólica de Faserland. Melhor: o simbolismo aqui, de par com a tendência antitranscendente do romance, não repete exatamente as passagens românticas do específico para o universal, senão torna o específico ainda mais específico e assim pouco ou nada simbólico. Agora não se fala de um carro, mas de um Porsche; não se fala de uma roupa, mas de uma Barbourjacke. Não interessa, de longe, espraiar o sentido e procurar atingir o geral, mas encolher com a localização e situar; e não interessa só a precisão, o detalhe, os "detalhes inúteis" (BARTHES), quase sempre anônimos do realismo literário, mas, porque as marcas têm nome e história bem registrados, sobressai em seu lugar, instante e monótona, a inutilidade detalhada do real. Trata-se no fundo de um estreitamento da experiência. A bem da verdade, não há mais sequer fundo, é a vida à superfície - e que experiência.

\footnotetext{
${ }^{5}$ Quando nos referirmos ao livro Faserland, de KRACHT (2002), serão indicados apenas os números de página.
}

Pandaemonium, São Paulo, v. 17, n. 23, Jun/2014, p. 68-82 


\section{Bonomo, D. - Vazio e fastio em Faserland}

As menções a nomes de empresas e marcas não patrocinam, está claro, o romance. É preciso admitir em tudo o distanciamento. Um erro comum à interpretação de Faserland é a identificação imediata do narrador com o autor, aplicando a este, de carne e osso, as censuras que se querem ver lançadas àquele, de papel e tinta. Trata-se de confusão costumeira e de certo modo já resolvida pela teoria da narrativa que particulariza, por exemplo, um "autor implícito" (Wayne C. ВоОTH). Assim são confundidos Christian Kracht e o autor produzido no texto de Faserland. É provável que coincidam em muita coisa. Há inclusive traços biográficos comuns. Mas os dois não são um só, nem podem ser iguais. A suposição da distância permite não ler o romance com chaves unicamente positivas. Ou seja, o leitor que recusa Kracht como quem recusa seu narrador e protagonista é semelhante ao leitor geralmente adolescente que se vê refletido no personagem e assume seus valores. Os sinais estão invertidos, mas a atitude é semelhante. São identificações simplistas, que não fazem justiça ao livro. O narrador de Faserland, como tantos outros na literatura moderna, é um desastre moral. Chamá-lo de "herói”, como fazem alguns de seus leitores, é hábito que surge deslocado. A figura é esnobe, cínica, provocadora, vaidosa, antipática. Recusá-lo não demanda muito esforço crítico.

Outro erro comum é insistir na trajetória do protagonista como "busca de sentido" (Sinnsuche). A ideia é corrente na teoria do romance e circunscreve um território caro à prosa de ficção. Trajetórias apontam com efeito para uma tentativa de sentido de personagens e leitores. Em Faserland, os elementos composicionais que encaminham para essa ideia são principalmente a viagem e as digressões da memória. Mas sua procura por sentido só faz zombar de si mesma. A viagem, visto que tem início, meio e fim coincidentes com os do romance, visto que tem sua duração e sugere algum acabamento - quando, além disso, não deixa de ser um recorte precário da vida -, aponta para a construção de um sentido que não vem. O movimento, a duração e o acúmulo não significam necessariamente construção de sentido. A gratuidade é maior em Faserland. O efeito é: os lugares, as coisas e as pessoas todas são substituíveis ou podem no mínimo ser deixadas para trás. Nesse caso, a constante intervenção de imagens do passado não propõe qualquer télos, não quer, ao menos, estimar a formação de uma personalidade, tão influente na tradição romanesca alemã. As imagens são, antes, pedaços do passado cuja relevância não se sabe mais, que estão aí, porque em 
Bonomo, D. - Vazio e fastio em Faserland

todo caso sobrevivem, agradáveis ou desagradáveis, como bolhas de ar que vêm à tona, estouram e somem, deixando nada ou quase nada.

Assim, Faserland é um livro que impõe uma dificuldade crítica não só sua, pois: como falar de um livro que, pelo visto, fala de nada? Não me refiro a uma pesquisa filosófica do nada, a uma tragédia ou abismo do nada. Mas ao nada constrangido e opaco do dia a dia. O romance quebra o silêncio com um investimento no vazio, como numa conversa sobre o tempo:

Para falar alguma coisa, falo que mais tarde vai chover, e Sergio acha que o tempo com certeza fica assim. Eu percebo que ele tem um sotaque e lhe pergunto de onde vem, e ele diz: da Colômbia. Depois acaba o assunto de algum modo e Sergio não fala mais, então acendo um cigarro e olho primeiro as unhas em minhas mãos e depois o mar. ${ }^{6}$

E entretanto todo romance sobre coisa nenhuma se converte num romance sobre alguma coisa. É possível nesse sentido estudar o próprio vazio e perceber o matiz inútil do romance. Há muitas espécies de inutilidade. Soprar anéis com a fumaça do cigarro ou reparar na marca Hanuta, estampada numa camiseta, e perguntar pela mania de abreviações dos alemães (35) são exemplos até comedidos. Um caso extravagante é o do amigo do protagonista que torra a herança familiar viajando pelo mundo a fim de descobrir quão disseminada foi uma daquelas canções grudentas da dupla Modern Talking. ${ }^{7}$ Não faltará interessado no assunto. Também a inutilidade é necessária, a seu modo saudável, e a mania de abreviação é com certeza curiosa. O próprio narrador recupera algumas abreviações da polícia nazista (Gestapo, Schupo, Kripo). ${ }^{8}$ Nem por isso, contudo, são imediatamente relevantes. No romance, pensamentos assim corroboram muitas vezes o ar de capricho, a petulância e o pouco caso, ainda que forneçam outras pistas. A extravagância do amigo que viaja o mundo conduzido pelos vestígios de uma esquisitice pop, por exemplo, permite além disso um sopro de Ausland (terra estrangeira) em Faserland (terra alemã).

\footnotetext{
${ }^{6}$ As traduções do texto de Faserland são minhas. "Um irgend etwas zu sagen, sage ich, daß es nachher regnen wird, und Sergio meint, daß das Wetter ganz bestimmt so bleibt. Ich merke, daß er einen Akzent hat, und frage ihn, woher er kommt, und er sagt: aus Kolombien. Dann geht uns irgendwie der Gesprächsstoff aus, und Sergio redet nicht weiter, also zünde ich mir eine Zigarette an und sehe erst auf meine Fingernägel und dann aufs Meer." (18)

${ }^{7}$ Grupo musical alemão da década de 80 responsável por hits como "You're my heart, you're my soul" e "You can win if you want". A sonoridade vem da música disco, conduzida por bateria eletrônica e linhas de baixo enfeitadas de sintetizadores, teclados e vocais em falsete.

${ }^{8}$ Respectivamente, Geheime Staatspolizei, Schutzpolizei, Kriminalpolizei. Hanuta é abreviação de Haselnußtafel, biscoito feito com avelã.
} 


\section{Bonomo, D. - Vazio e fastio em Faserland}

Porque, no geral, o romance é sufocante. Apesar de consistir numa viagem, não é a variedade e o inesperado que chamam a atenção. Daí que as histórias de Alexander, o amigo viajante, e as recordações recorrentes do narrador terminem por ventilar o ambiente abafadiço de Faserland. Assim também a fantasia de um futuro ao lado de Isabella Rossellini. São intervalos num presente total, surdo. O romance é eu aqui, na Alemanha, e agora. Tudo na primeira pessoa e presente do indicativo. Como no refrão "eu acendo um cigarro", que só adensa a atmosfera opaca.

Faserland é bom exemplo, supondo que, com a literatura pop dos anos de 1990, após um desdobramento demorado dos temas vinculados à dificuldade do discurso acerca do passado nazista, o presente reclamou seu lugar na literatura alemã. Isso não significa que, nele, o assunto nazista seja matéria morta. Isso não significa que, nele, o assunto nazista seja matéria morta. Ao contrário, surge repetidamente: férias de Göring em Sylt (17), as abreviações mencionadas (35), bombardeio de Hamburgo (47) e filme de Leni Riefensthal (61). Assuntos assim, no romance, não só aparecem sem maior gravidade - quer dizer, sem promover mudanças maiores no registro discursivo indiscriminadamente descomprometido do livro - senão convivem com usos parcialmente esvaziados como aquele que faz de "nazista" xingamento banal. Nada elimina o desconforto. Já se falou aliás das contradições do estranhamento no interior da própria cultura e também mediante a exposição à cultura alheia presente na obra de Kracht. ${ }^{9} \mathrm{O}$ incômodo é constante, o mal-estar geral, nem Ausland nem Faserland, finalmente, salvam.

\section{Um antirromance de aventuras}

O universo de Kracht - o seu próprio, com suas temporadas em diferentes localidades asiáticas, e o de sua literatura, que conta com relatos como os de Ferien für immer, Der gelbe Bleistift e Gebrauchsanweisung für Kathmandu und Nepal - é também o de um viajante. Imperium, o romance mais recente, vai a uma ilha da Nova Guiné Alemã com

\footnotetext{
9 "Ebenso wenig, wie der Aufenthalt in der Fremde Krachts deterritorialisierten Figuren ein erfülltes Dasein ermöglicht, vermag die Rückkehr in die Heimat ihre Probleme zu lösen: Gängige Konstruktionen kultureller Differenz werden in seinem Werk vermittels eines generellen Nihilismus nivelliert." (HERMES 2011: 188)
} 


\section{Bonomo, D. - Vazio e fastio em Faserland}

um viajante do passado, o curioso August Engelhardt (1875-1919), que, no início do século XX, estabeleceu nos trópicos uma seita denominada Kokovorismus, espécie de culto à luz solar, nudismo e dieta à base de coco. Na verdade, mais que exotismo, o passado e o distante, fundamentais para toda a literatura, não são incomuns à de língua alemã atual. São elementos composicionais que, entre outras coisas, prometem quem sabe uma ou mais aventuras. Aventura não sempre no sentido trivial ou clássico de um Karl May. Há nos últimos anos exemplares aventurescos diversificados, como os de Ilija Trojanow (Der Weltensammler, 2006) ou Christoph Ransmayr (Die Schrecken des Eises und der Finsternis, 1984). Tschick (2010), de Wolfgang Herrndorf, é outra aventura. ${ }^{10}$ Mas Faserland sugere, antes, um antirromance de aventuras. Nesse sentido, superar a dificuldade de falar sobre um romance que fala de nada pode parecer simplesmente falar daquilo que ele não é. Mas ele não é muita coisa, e não só aborrece dizer o que ele é referindo tudo quanto ele não é, como assemelha a método escolástico. Por isso, ainda por via negativa, importa mais dizer o que ele é virado pelo avesso.

Com os avanços da comunicação e do transporte durante os séculos precedentes e sua aceleração nos últimos tempos tornou-se lugar-comum falar em encolhimento do globo. A ideia, simplificando, é: nada mais pode ser descoberto, não há paragens e povos preservados do contato com a civilização que faz negócios e converte diferenças na semelhança generalizada e insossa da vida como conjunção de trabalho e distração. O esgotamento, apesar disso, tem por certo algo de apressado. Nesse mundo, ainda que tudo pareça disponível, distâncias vão longe de estar superadas e promovem, enquanto procuram verificar suas possibilidades menos vulgarizadas, sempre mais viagens. A permanência da aventura como motivo literário é indicativo de seu interesse. Voltar ao passado ou ir ao futuro, não importa se a uma realidade melhor ou pior, como viajar aos limites da paisagem, é também um modo de arejar a mesmice do presente e a preguiça do esgotamento precipitado. José Paulo PAES notava que, em face do encurtamento da Terra, a ficção de aventuras teria dado lugar, ainda recentemente, à ficção científica, capaz de explorar territórios ignorados como os dos anos-luz que, praticamente imensuráveis, arriscam medir a imensidão do cosmo (1990: 23). A ficção sideral é

\footnotetext{
${ }^{10}$ A menção a Tschick tem que ver com o contexto em que apresentei o presente texto pela primeira vez, durante a $8^{\mathrm{a}}$ Jornada e $1^{\circ}$ Simpósio de Literatura Alemã, na Universidade de São Paulo, em outubro de 2013. No evento, Moritz Baßler ministrou um breve curso sobre o livro de Wolfgang Herrndorf. Há traduções brasileiras dos três títulos citados: Tchick, de Herrndorf (tradução de Claudia Abeling, Tordesilhas, 2011); O colecionador de mundos, de Trojanow (tradução de Sergio Tellaroli, Companhia das Letras, 2010); e Pavores de gelo e trevas (tradução de Marcelo Backes, Estação Liberdade, 2010).
} 


\section{Bonomo, D. - Vazio e fastio em Faserland}

assim uma expansão espaçotemporal da aventura por terras e mares. Faserland, no entanto, embora feito de deslocamentos, sai pouco do lugar.

Mas Faserland espelha um romance de aventuras no que respeita à horizontalidade de sua organização. Apesar do bom número de digressões, diferentemente de romances psicológicos ou de análise, conhecidos por seus mergulhos demorados nas águas do pensamento, Faserland é raso e breve nos desvios. A organização é portanto do plano horizontal, como numa aventura clássica. A narrativa é sobretudo obra da sequência dos acontecimentos. Isso em plano estrutural. Contudo, a sequência agora é nada atrás de nada. O sentimento de aventura é só uma recordação do momento no aeroporto que antecede a viagem a uma ilha grega frequentada por homossexuais (133). ${ }^{11}$ A aventura, em Faserland, nunca se configura e mais: seus elementos, aqueles conhecidos do romance de aventuras, ${ }^{12}$ são negados de tal maneira que resultam justamente na imagem invertida que esse espelhamento supõe. A seguir, recorrendo a seis justificativas, vê-se o porquê.

- no romance de aventuras clássico, o herói é no geral figura tenaz e irreprimível, muitas vezes exemplo moral e repositório de virtudes, implicando simpatia e admiração; em Faserland, o protagonista antipático, que abandona amigos da mesma maneira que abandona roupas e carros, dono de opiniões e comportamentos “controversos", para dizer pouco, é facilmente recusável;

- no romance de aventuras há em geral alguma missão, um objetivo ou uma série de objetivos que incentivam a ação e que são atingidos por meio de uma enfiada de peripécias; em Faserland, a viagem é à toa, as finalidades inexistentes e a história tem poucos grãos de sal;

\footnotetext{
${ }^{11}$ A propósito, ideia excelente a de Baßler (2002: 113), que assinalou o conflito gay do livro. "Faserland ist überdies konsistent als Problemstudie über ein verpaßtes Coming-out lesbar. Die Erlebnisse der IchFigur mit den (männlichen) Freunden und eine Beinahe-Vergewaltigung durch eine Party-Bekanntschaft werden unterfüttert durch zahlreiche Erinnerungen (z. B. an einen Schwulen-Strand auf Kreta), die in diese Richtung deuten. Am Ende wird das geradezu in eine Art Allegorie gekleidet, wenn der Held sich von Zürich aus nach Kilchberg aufmacht, um das Grab Thomas Mann zu suchen, es aber wegen einbrechender Dunkelheit nicht finden kann."

${ }^{12}$ Os critérios para a definição de um romance de aventuras apresentados a seguir derivam principalmente - e não sistematicamente - do texto de José Paulo Paes, "As dimensões da aventura", incluído em $A$ aventura literária (1990).
} 


\section{Bonomo, D. - Vazio e fastio em Faserland}

- no romance de aventuras, um pouco como no romance de formação, há estações de iniciação e aprendizado, construindo sentidos com que se amarra a vida do herói; em Faserland, quase nada fica, os sentidos são frustrados e o protagonista não deixa o romance acrescido de qualquer transformação;

- no romance de aventuras, os espaços são principalmente abertos, o exótico seduz e as paisagens instauram a nostalgia de estar distante; em Faserland, quando não está em locais fechados, como quartos de hotel, bares e festas, o protagonista cruza a Alemanha, a pátria do título, onde as paisagens são todas alemãs e a monotonia passa via Autobahn, Deutsche Bahn, Aeroporto de Frankfurt, cidades como Heidelberg até à Suíça;

- no romance de aventuras de corte clássico, o desfecho reserva comumente para o herói uma recompensa justa e feliz; em Faserland, o último capítulo traz a "solução" restrita da paisagem suíça e a quase decepção de não encontrar, em Kilchberg, o túmulo de Thomas Mann;

- no romance de aventuras, é comum supor o predomínio da leitura divertida, decorrente em parte da presença de surpresas e perigos que contagiam a atenção; em Faserland, mesmo que divertido em determinadas passagens, predomina uma espécie de aborrecimento.

Neste ponto, devo esclarecer o aborrecimento. ${ }^{13}$ A escolha de falar num antirromance de aventuras é já sua condução. Nesta altura, a incontornabilidade da mesmice e do nada em Faserland é clara. Mas o que poderia sugerir um romance da pura apatia não o faz tão imediatamente. Há muitas coisas com que o narrador simpatiza e outras tantas com que antipatiza. A antipatia é especialmente notável: o personagem repele pessoas que "estouram" um champanhe (22), acha horrorosa a composição do interior do ICE, os

\footnotetext{
${ }^{13} \mathrm{Na}$ verdade, trata-se de pesquisa maior. "Aborrecimento", aqui, adquire mais de um sentido: é contrapeso a uma visão ideológica da experiência literária associada aos prazeres da leitura; é parte de uma dinâmica de afirmações e recusas definidora dos rumos da história literária; é uma realidade formal verificada em aspectos da narrativa romanesca; é uma realidade temática observada principalmente em romances a partir do século XIX.
} 
Bonomo, D. - Vazio e fastio em Faserland

trens velozes que cruzam a Alemanha (24), acha deprimente a cidade de Frankfurt (82), nazistas os aposentados leitores do jornal Welt am Sonntag (93) e assim por diante até que sobressaia, no conjunto, a imagem antipática do narrador. Ela adquire porém um sentido político principalmente quando, nas últimas páginas, se mostra a mesma crítica franca do "torrão natal" do título. Ao se imaginar morando na Suíça com Isabela Rosellinni e com os filhos que resultariam dessa união, ou seja, sua ficção atingindo estágios avançados, diz como falaria a eles sobre a Alemanha, configurando um quadro cômico - simples porque feito de adições e difícil porque adiciona muita coisa - e intolerante:

Eu contaria a eles sobre a Alemanha, sobre o grande país ao norte, sobre a grande máquina que, lá abaixo na planície, se constrói. E contaria sobre as pessoas, sobre os escolhidos, que vivem no interior da máquina, que têm que dirigir bons carros e tomam boas drogas e bebem bom álcool e têm que ouvir boa música, enquanto todos ao redor fazem o mesmo, apenas um pouquinho pior. E que os escolhidos só podem continuar vivos por acreditarem que poderiam fazer as coisas um pouco melhor, com um pouco mais de rigor, um pouco mais de estilo. ${ }^{14}$

E:

Contaria sobre os alemães, sobre os nacional-socialistas com seus pescoços despelados, sobre os construtores de foguetes, que metem no bolso de seus jalecos brancos uma caneta-tinteiro bem alinhada. Eu contaria sobre a seleção dos prisioneiros, sobre os homens de negócios com seus ternos mal cortados, sobre os sindicalistas, que votam sempre no SPD, como se alguma coisa realmente dependesse disso, e sobre os grupos autônomos, com suas cozinhas populares e recusa a esmolas. ${ }^{15}$

E:

Eu também contaria sobre os homens que vão à Tailândia porque se sentiriam assim poderosos e amados, e sobre as mulheres que vão à Jamaica porque também querem ser poderosas e amadas. Contaria sobre os garçons, sobre os estudantes, os motoristas de

\footnotetext{
14 "Ich würde ihnen von Deutschland erzählen, von dem großen Land im Norden, von der großen Maschine, die sich selbst baut, da unten im Flachland. Und von den Menschen würde ich erzählen, von den Auserwählten, die im Inneren der Maschine leben, die gute Autos fahren müssen und gute Drogen nehmen und guten Alkohol trinken und gute Musik hören müssen, während um sie herum alle dasselbe tun, nur eben ein ganz klein bißchen schlechter. Und daß die Auserwählten nur durch den Glauben weiter leben können, sie würden es ein bißchen besser tun, ein bißchen härter, ein bißchen stilvoller." (152-53)

15 "Von den Deutschen würde ich erzählen, von den Nationalsozialisten mit ihren sauber ausrasierten Nacken, von den Raketen-Konstrukteuren, die Füllfederhalter in der Brusttasche ihrer weißen Kittel stecken haben, fein aufgereiht. Ich würde erzählen von den Selektierern an der Rampe, von den Geschäftsleuten mit ihren schlecht sitzenden Anzügen, von den Gewerkschaftern, die immer SPD wählen, als ob wirklich etwas davon abhinge, und von den Autonomen, mit ihren Volxküchen und ihrer Abneigung gegen Trinkgeld." (153)
}

Pandaemonium, São Paulo, v. 17, n. 23, Jun/2014, p. 68-82 


\section{Bonomo, D. - Vazio e fastio em Faserland}

táxi, os nazis, os aposentados, as bichas, os que fecham financiamentos, os publicitários, os DJs, os traficantes de ecstasy, os sem-teto, os jogadores de futebol e os advogados. ${ }^{16}$

A intolerância da enumeração é também do aborrecimento. Não só por ser recurso narrativo que impõe ritmo estacionário ou uma temporalidade orbitária, quer dizer, uma temporalidade que, sempre um tanto igual a si mesma, evolui. Mas porque na palavra "aborrecimento" há primeiramente o sentido de "horror a", de aversão a alguma coisa, e esse sentido é o de Faserland.

A sociedade que aí se recusa é dos outros, publicitários e advogados, mas também sua. $\mathrm{O}$ narrador participa evidentemente dessa Alemanha que repele. Pode ser anticorpo, mas não é corpo estranho. Sua figuração lenta e aborrecida é anticorpo numa sociedade que de certa maneira continua a regra acelerada dos dias atuais e que já foi definida, por exemplo, pelo sul-coreano Byung-Chul HAN (2010), como "sociedade do cansaço" (Müdigkeitsgesellschaft). A expressão propõe uma sociedade em que predominam justamente variações do mesmo, em que a violência reside justamente na positividade, na saturação e na exaustão. Nela, não há sistema imunológico, por assim dizer, recorrendo a suas metáforas; a sociedade assim definida não é a "disciplinar" de Foucault, com prisões e hospícios, mas uma sociedade do "desempenho" ou do "rendimento" (Leistungsgesellschaft), com escritórios e academias de ginástica, uma sociedade yes we can e seus conseguintes esgotamentos, infartos e depressões. Ao questionar as viagens do amigo a países do Terceiro Mundo, o narrador de Faserland diz que não há razão em tais viagens, a menos que se dedique a uma ocupação que não existe mais: a do ocioso (KRACHT 2002: 133).

Faserland, a meu ver, é principalmente um livro do fastio, palavra que conjuga cansaço, aversão e aborrecimento. O refrão "acendo um cigarro" é a um só tempo a repetição e o mal-estar. Há no romance uma quantidade de cigarros consumidos só comparável à de uma película com Humphrey Bogart. O leitor, se quiser e puder, experimenta o enjoo. Daí a importância do sentido olfativo em Faserland. Há sensações boas, o narrador experimenta algo bom com um cheiro de carro novo, cheiro de mar no

\footnotetext{
16 "Ich würde auch erzählen von den Männern, die nach Thailand fliegen, weil sie so gerne mächtig und geliebt wären, und von den Frauen, die nach Jamaica fliegen, weil sie ebenfalls mächtig und geliebt sein wollen. Von den Kellnern würde ich erzählen, von den Studenten, den Taxifahrern, den Nazis, den Rentnern, den Schwulen, den Bausparvertrags-Abschließern, von den Werbern, den DJs, den EcstasyDealern, den Obdachlosen, den Fußballspielern und den Rechtsanwälten.” (153)
} 


\section{Bonomo, D. - Vazio e fastio em Faserland}

início do romance ou o cheiro das lojas de flores e delicatéssens na Suíça, no fim. Mas, em conformidade com a embriaguez contínua, predominam as sensações enfastiantes por efeito de pessoas que cheiram a viagem (28), bocas, velhos que cheiram como coisas velhas (47), o combustível do avião e o perfume das mulheres no aeroporto (54), o iogurte de pêssego derramado na roupa (59), a urina caindo sobre os aromatizantes do mictório (80), o quarto mofado em Heidelberg (91). São marcações olfativas constantes. Algumas mesmo proustianas, como o cheiro do sabonete que faz voltar um episódio da infância na ilha da Madeira (88) e o cheiro da cera que faz lembrar o primeiro amor, cuja história, no entanto, tem desfecho escatológico (32-33).

A propósito, o elemento escatológico converte o romance em verdadeira coprologia. Imagens de um cachorro defecando, urina respingada nos lábios, excremento atirado à cabeça, vômito atrás de vomito e tudo, estranhamente, vazado em estilo meio sóbrio, meio infantil. A coprologia de Faserland é aliás agressão e humor também infantis, e vontade de confronto, já se notou, com as caras burguesas mais afeitas à "civilidade". ${ }^{17} \mathrm{O}$ aborrecimento e o fastio, aí, podem passar pelo escatológico, mas podem também ser o efeito prolongado de uma substância, o excesso de cigarros e a hipersensibilidade olfativa de Faserland. São também a recusa de uma realidade da qual o narrador não é poupado, ele próprio consistindo numa aberração. Mas é justamente essa insistência intransigente e negativa em questões atuais que permite a eficiência crítica do romance. Sua leitura exige essa mesma insistência, porque Faserland, ainda bem, aborrece.

\section{Referências bibliográficas}

BAßLER, Moritz. Der deutsche Pop-Roman. Die neuen Archivisten. München, C. H. Beck, 2002. BEUSE, Stefan. "154 schöne weiße leere Blätter" - Christian Krachts Faserland. In: Freund, Wieland/Freund, Winfried (ed.). Der deutsche Roman der Gegenwart. München: Wilhelm Fink, 2001: 150-155.

\footnotetext{
17 'Das Interesse, mit welchem der Erzähler die 'große Kackwurst' eines Hundes betrachtet oder die Faszination, mit der eine sich erbrechende Frau beobachtet wird sowie die Intensität, mit der jeder Gang zur Toilette erwähnt oder sogar in allen möglichen Folgen durchdacht wird, wiederholt kindliche Entwicklungsstufen und eine pubertäre Auflehnung, die bürgerliche Tabus bewusst verletzt. (GLAwION; NOVER 2009: 106)
} 
Bonomo, D. - Vazio e fastio em Faserland

DiDERot, Denis. O sobrinho de Rameau. Tradução de J. Guinsburg. São Paulo: Perspectiva, 2006.

DIEZ, Georg. Die Methode Kracht. In: Spiegel, Februar 2012: 100-103.

GANSEL, Carsten. Adoleszenz, Ritual und Inszenierung in der Pop-Literatur. In: Arnold, Heinz Ludwig/Schäfer, Jörgen (ed.). Text+Kritik Pop-Literatur. München: Text+Kritik, 2003: 234-257.

Glawion, Sven/Nover, Immanuel. Das leere Zentrum - Christian Krachts "Literatur des Verschwindens". In: Tacke, Alexandra/Weyand, Björn (ed.). Depressive Dandys Spielformen der Dekadenz in der Pop-Moderne. Köln: Böhlau, 2009: 101-120.

HAN, Byung-Chul. Müdigkeitsgesellschaft. Berlin: Matthes \& Seitz, 2010.

HECKEN, Thomas. Die verspätete Wende in der Kultur der 1990er Jahre. In: Grabienski, Olaf/Huber, Till/Thon, Jan-Noël (ed.). Poetik der Oberfläche - Die deutschsprachige Popliteratur der 1990er Jahre. Berlin, Boston: De Gruyter, 2011: 13-26.

HERMES, Stefan. Tristesse globale - Intra- und interkulturelle Fremdheit in den Romanen Christian Krachts. In: Grabienski, Olaf/Huber, Till/Thon, Jan-Noël (ed.). Poetik der Oberfläche - Die deutschsprachige Popliteratur der 1990er Jahre. Berlin, Boston: De Gruyter, 2011: 187-205.

ILLIES, Florian. Generation Golf. Eine Inspektion. 13. Aufl. Fischer, Frankfurt am Main 2011. [2000].

KRACHT, Christian. Faserland. München: DTV, 2002.

MERTENS, Mathias. Robbery, assault, and battery - Christian Kracht, Benjamin v. StuckradBarre und ihre mutmaßlichen Vorbilder Bret Easton Ellis und Nick Hornby. In: Arnold, Heinz Ludwig/Schäfer, Jörgen (ed.). Text+Kritik Pop-Literatur. München: Text+Kritik, 2003: 201-217.

NiETZSCHE, Friedrich. Além do bem e do mal - Prelúdio a uma filosofia do futuro. Tradução de Paulo César de Souza. São Paulo: Companhia das Letras, 2005.

PAES, José Paulo. A aventura literária. Ensaios sobre ficção e ficções. São Paulo: Companhia das Letras, 1990.

RADISCH, Iris. Beschwerde beim Dienstherrn. In: Die Zeit, 23. Februar 2012.

recebido em: 10/03/2014

aceito em: 09/04/2014 